Revista de

Contabilidade e

Organizações

www.rco.usp.br
DOI: http://dx.doi.org/10.11606/rco.v7i18.55610
Journal of

Accounting and

Organizations

\title{
Securitização como mecanismo de gerenciamento de resultados em bancos brasileiros
}

\author{
Gilberto Ataide Camara ${ }^{\mathrm{a}}$; Fernando Caio Galdi ${ }^{\mathrm{b}}$ \\ ${ }^{a}$ Faculdade Pitágora \\ ${ }^{b}$ Fundação Instituto Capixaba de Pesquisa em Contabilidade, Economia e Finanças
}

\section{Informações do Artigo}

Histórico do Artigo

Recebido: 15 Maio 2013

Aceito: 30 Outubro 2013

\section{Palavras chave}

Securitização de Ativos

Gerenciamento de Resultados

FIDC

Accruals

Instituições Financeiras

\begin{abstract}
Resumo
Este estudo tem como objetivo investigar a prática de gerenciamento de resultados nas instituições financeiras brasileiras por meio da realização de operações de securitização. Em linha com a literatura internacional, verificou-se uma relação negativa entre os ganhos com securitização e os ganhos antes da securitização das instituições financeiras. Adicionalmente foi identificada uma relação negativa dos ganhos com securitização e a variação dos ganhos antes da securitização entre o exercício atual e o exercício anterior. Finalmente, não foram encontradas evidências de que a estruturação das operações com FIDCs influenciam o resultado com a transferência.
\end{abstract}

Copyright (C) 2013 FEA-RP/USP. Todos os direitos reservados

\section{INTRODUÇÃO}

As operações de securitização alocam de maneira eficiente risco e capital (SCHWARCZ, 2009). Essas operações trazem benefícios para as empresas, pois possibilitam o acesso ao mercado de capitais de maneira direta, na maioria dos casos a um custo inferior ao que as empresas obteriam se emitissem títulos de dívida da maneira tradicional. Contudo, o mecanismo de contabilização das operações de securitização pode ser utilizado de maneira a antecipar o registro de ganhos, causando a possibilidade de seu uso para o gerenciamento de resultados por parte das empresas. Nesse contexto, o presente trabalho tem como objetivo investigar se as instituições financeiras brasileiras lançam mão de operações de securitização (cessão e/ou transferência) de ativos financeiros com o intuito de gerenciar seus resultados.

Dechow, Myers e Shakespeare (2010) estudaram o gerenciamento de resultados decorrente de operações de securitização no mercado norte-americano. As autoras encontraram uma relação negativa entre os ganhos de atividades de securitização e os ganhos de

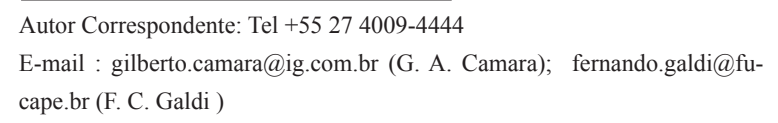

Fundação Instituto Capixaba de Pesquisa em Contabilidade, Economia e Finanças. Av. Fernando Ferrari, 1358 Goiabeiras 29075-010 - Vitoria, ES - Brasil atividades de não securitização. Outra relação negativa foi detectada entre os resultados com securitização e os resultados antes da securitização, nos quais o ganho antes da securitização foi determinado por meio do resultado líquido do exercício deduzido do ganho com securitização. Além disso, foi identificada a correlação negativa entre o ganho com securitização e a variação negativa do resultado antes da securitização do exercício atual com o exercício anterior.

Finalmente, Dechow et al. (2010) examinaram as consequências das regras contábeis que permitem a baixa dos recebíveis quando estes são transferidos a uma Sociedade de Propósito Específico (SPE). Quando uma empresa vende os recebíveis, ela recebe caixa e qualquer diferença é reconhecida como ganho ou perda. A baixa de tais recebíveis fornece ampla oportunidade para manipular o resultado, uma vez que os fluxos de caixa retidos devem ser reconhecidos a valor justo, mesmo não havendo valor de mercado ativo. Gestores utilizam a discricionariedade obtida das regras contábeis do valor justo para registrar ganhos maiores e isso pode ser oneroso, pois um excesso de otimismo no período atual aumenta a probabilidade de registrar futuras perdas por impairment.

Os resultados de Dechow et al. (2010) mostram que a securitização tem um impacto relevante no resultado, onde $13 \%$ das empresas reportam ganhos com securitização, convertendo uma perda no resultado contábil em lucro e 38\% aumentaram o resultado contábil. No entanto, segundo os autores não foi possível afirmar que a regra contábil do valor justo permite o gerenciamento de 
resultados por parte dos gestores.

No Brasil, encontra-se como alternativa de securitização às SPE, o Fundo de Investimento de Direitos Creditórios (FIDC) que fortalece esse processo como uma modalidade a mais de captação de recursos, inclusive para as instituições financeiras (IFs). Em contrapartida, o FIDC oferece aos investidores a oportunidade de aplicar recursos em ativos com riscos menores e com taxas compatíveis com as oferecidas pelo mercado (Associação Nacional das Instituições do Mercado Financeiro [ANDIMA] e Câmara de Custódia e Liquidação [CETIP], 2006).

Com base nos antecedentes apresentados, a questão da pesquisa deste trabalho consiste na seguinte pergunta: As Instituições Financeiras (IFs) adotam a prática de securitização (cessão e/ou transferência) de ativos financeiros como instrumento para gerenciar seus resultados?

Dentre os objetivos específicos circunscritos neste estudo, pode-se citar:

I - verificar como se comportam os resultados antes da securitização em relação aos resultados com securitização;

II - identificar como ocorrem as variações nos resultados antes da securitização em relação aos resultados com securitização.

Goulart (2007) destaca que o gerenciamento de resultados pode ocasionar prejuízos à transparência empresarial e possíveis impactos negativos à eficiência do mercado, bem como à solidez do sistema financeiro. Em relação às IFs, em particular, estas apresentam interesses na suavização de resultados (income smoothing), como uma forma de gerenciá-los apresentando uma regularidade de lucros e reduzindo a volatilidade nesses resultados.

O estudo da cessão e/ou transferência de direitos creditórios das IFs aos FIDCs é um tema relevante e oportuno no mercado brasileiro. Um exemplo disso foi a recente determinação de republicação do balanço de 2008 do Banco Cruzeiro do Sul S.A. (BCSULSA) pela Comissão de Valores Mobiliários (CVM), devido à ausência da consolidação de um de seus FIDCs (BCSULSA, 2011). Outro fato relevante se deu em relação às divergências apuradas pela CVM junto ao BCSULSA, pelo fato de este banco ter utilizado possíveis mecanismos por meio de cessão de direitos creditórios aos seus FIDCs, a fim de melhorar seu balanço (Comissão de Valores Mobiliários [CVM], 2010).

Usando informações das operações de securitização realizadas pelas instituições financeiras brasileiras de 2002 a 2010, os resultados deste estudo evidenciam que os gestores utilizam a discricionariedade existente nas operações de cessão e transferência para suavizar o resultado das instituições financeiras, contudo não é possível discernir se o gerenciamento de resultados observado é relativo a: i) estimativa do ganho de securitização, ii) características dos ativos objetos de cessão/transferência ou, iii) decisões negociais, como por exemplo, a taxa de desconto.
O restante do trabalho está dividido em mais quatro etapas conforme segue: na seção dois apresenta-se o referencial teórico; na três, discutiu-se acerca da metodologia; na quatro, apresentaram-se os resultados; na cinco, descreveram-se as considerações finais e, por fim, as referências.

\section{REFERENCIAL TEÓRICO}

$\mathrm{N}$ literatura internacional, $\mathrm{O}$ estudo do gerenciamento de resultadol é conhecido como Earnings Management, e não é uma prática nova nas pesquisas em contabilidade. Estudos sobre escolhas contábeis e manipulação e/ ou gerenciamento de números contábeis representam uma das áreas que mais tem recebido atenção dos pesquisadores, McNichols (2000), Kothari (2001), Fields, Lys e Vincent (2001). O interesse pelo assunto tomou maior significância, a partir de 2001, com o advento dos escândalos corporativos registrados nos Estados Unidos, deixando evidente a facilidade no uso de práticas para gerenciar resultados PAULO \& SANTOs, 2006).

Carvalho, Paulo e Rodrigues (2007, p. 217) definem o gerenciamento de resultados como sendo a adoção de práticas contábeis por via da qual se objetiva a promoção de alterações nos resultados, cujas tipificações são:

Bad Earnings Management: Representa gerenciamento inapropriado dos resultados por meio da criação de artifícios contábeis ou alterações de estimativas além do ponto adequado, como, por exemplo, o reconhecimento prematuro das receitas e a expressiva redução de provisões; e

Good Earnings Management: Práticas adequadas de gerenciamento de resultados que configuram uma boa administração de negócios e produzem valor aos acionistas, tais como respeitar orçamento, ter metas, supervisionar resultados, organizar operações internas, motivar empregados e prover informações aos investidores (CARVALHO et al., 2007, p. 217).

Considerando as finalidades para as quais os gestores adotam as práticas de gerenciamento de resultados, podese destacar como as principais: a) influenciar a percepção do mercado de ações; b) aumentar a compensação dos administradores; c) potencializar a obtenção de empréstimos; e, d) evitar a intervenção de reguladores (CUPERTINO \& MARTINEZ, 2008, p.74).

As características das operações de securitização ensejam oportunidades o para o gerenciamento de resultados. Securitização é uma operação financeira que converte recebíveis futuro em títulos negociáveis, os quaie serão disponibilizados no mercado no presente. Esses títulos são vendidos a investidores interessados em receber os fluxos de caixa gerados por esses ativos (GALDI et al., 2006).

Ao promoverem uma venda dos recebíveis a uma SPE, 
existe um risco moral, já que os gestores se deparam com incentivos para reduzir os padrões de créditos dos quais a empresa não suporta o custo total da inadimplência. Esse fato pode acarretar uma seleção adversa no sentido de vender os títulos de menor qualidade. A natureza do risco do negócio pode ser alterada em função de os investidores perderem o interesse em comprar títulos securitizados, e as empresas originadoras desses ativos podem tornar o caixa mais restrito (DECHOW et al., 2010).

Há quatro tipos de securitização de recebíveis: i) afetação (raramente utilizado), que apenas vincula os direitos creditórios aos títulos ou valores mobiliários emitidos; ii) SPE - é uma prática bem comum no Brasil; iii) trust / securitizadora; ou iv) FIDC, o qual será mais detalhado adiante. Pode-se efetivar uma operação de securitização por meio de recebíveis "genéricos", imobiliários e de exportação; estes recebíveis são denominados de direitos creditórios (GALDI et al., 2006).

As securitizações ocorrem normalmente na indústria de serviços financeiros (empréstimos corporativos, empréstimos habitacionais, empréstimos pessoais), mas também são comuns no varejo (cartões de crédito), bens de produção (aluguéis de automóveis). A venda de recebíveis para obter caixa e r-emprestar a novos clientes é uma parte integral do modelo de negócio (DECHOW et al., 2010).

Para o sucesso da operação, faz-se de primordial relevância a boa qualidade da carteira dos recebíveis. Nesse prisma, o que o mercado leva em consideração é a qualidade desses recebíveis, e não a situação financeira da empresa originadora (IUDÍCIBUS; MARTINS; GELBECKE; SANTOS, 2010).

Um mecanismo muito utilizado no mercado brasileiro para a realização de operações de securitização ocorre por meio do veículo Fundo de Investimento em Direito Creditório (FIDC). O FIDC foi criado no Brasil em 2001, após um ambiente de limitação de crédito, fortalecendo, como uma alternativa, a captação de recursos para empresas no Brasil, inclusive para assIFs. O FIDC é uma alternativa de securitização às SPE, dispensando a necessidade de constituir uma sociedade anônima, reduzindo assim os custos de operação, inclusive tributo, como o IRPJ, CSSL, Cofins e PIS (ANDIMA; CETIP, 2006).
Para regular os FIDCs, os fundos de recebíveis utilizados como entidades de distribuição de títulos para efeitos de securitização, a CVM emitiu a Instrução $\mathrm{n}^{\circ}$ 356, de 17 de Dezembro de 2001, alterada em diversas ocasiões pelas Instruções CVM n ${ }^{\circ} 393$, de 22 de julho de $2003, n^{\circ} 435$, de 05 de julho de 2006, n ${ }^{\circ} 442$, de 08 de dezembro de 2006, $\mathrm{n}^{\circ} 446$, de 19 de dezembro de 2006, e $\mathrm{n}^{\circ} 484$, de 21 de julho de 2010

Em relação ao patrimônio líquido (PL) do FIDC, 50\% são aplicados em direitos creditórios, que são os fluxos de caixa futuros das operações comerciais. Por outro lado, em relação ao PL dos Fundos de Investimento em Cotas de Fundos de Investimento em Direitos Creditórios (FICFIDC), 95\% se destinam à aplicação em cotas de FIDC iGALDI et al., 2006).

As cotas dos FIDCs podem ser do tipo sênior, com preferência no recebimento e resgate; enquanto as do tipo subordinad, têm o resgate subordinado aos das cotas seniores (IUDÍCIBUs et al., 2010).

O FIDC é mais uma fonte de captação de recursos, a um preço mais baixo que os praticados no mercado, a partir do momento em que uma empresa originadora de direitos creditórios realiza uma cessão ou venda desses direitos aos FIDCs por uma dada taxa de desconto. Posteriormente, o FIDC emite e disponibiliza cotas de títulos e valores mobiliários aos investidores interessados em adquirir esses fluxos de caixa. É necessário ressaltar que, uma vez realizada a venda ou cessão de crédito, a empresa cedente não poderá renegociar seus créditos com seus clientes. Uma forma encontrada para contornar essa restrição é a substituição do lastro, quando do atraso ou inadimplemento (ANDIMA; CETIP, 2006).

As garantias oferecidas aos investidores podem ser subordinação das cotas e seguros, fato que ajuda na redução do risco específico. Para melhor avaliação do fundo, faz-se de primordial importância selecionar bons direitos creditórios e contratar agentes com capacidade reconhecida pelo mercado (ANDIMA; CETIP, 2006).

O fundo é composto basicamente pela empresa originadora, administrador do fundo, custodiante e agência de rating. A Figura 1 apresenta um modelo de uma estrutura genérica da operação de cessão com os FIDCs.

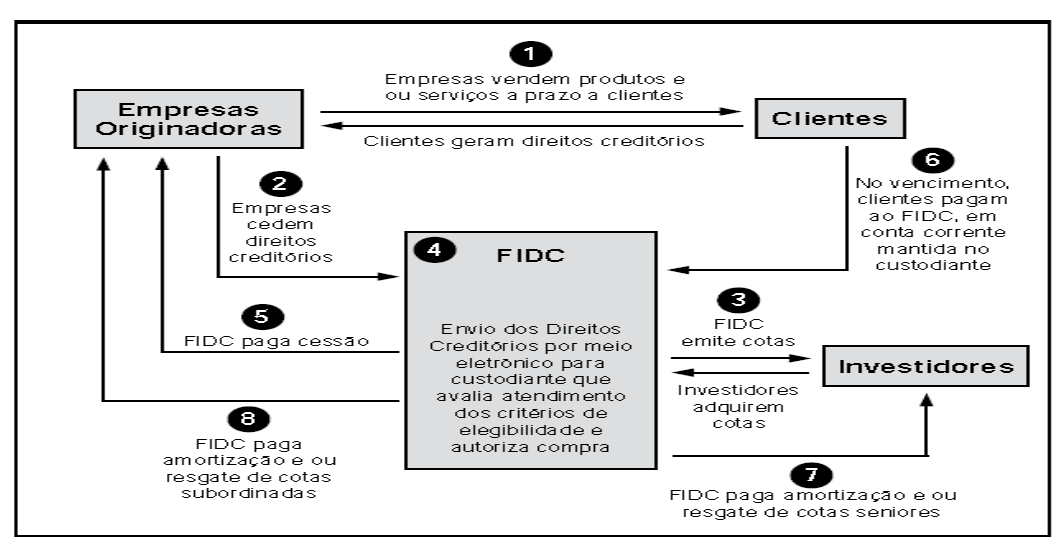

Figura 1. Passo a passo da securitização com base em FIDC 
No Brasil, a securitização, por meio de FIDCs, vem evoluindo bastante com passar dos anos, pois oferece às empresas originadoras de créditos uma forma de captar recursos com taxas inferiores às praticadas pelo mercado. Em contrapartida, oferece aos investidores oportunidade de aplicar recursos em ativos com riscos menores e com taxas compatíveissàs oferecidas pelo mercado (ANDIMA; CETIP, 2006).

A Figura 2 demonstra a evolução do saldo dos FIDCs registrados na CVM em PL (R \$ milhões) e em quantidade de registros (unidade).

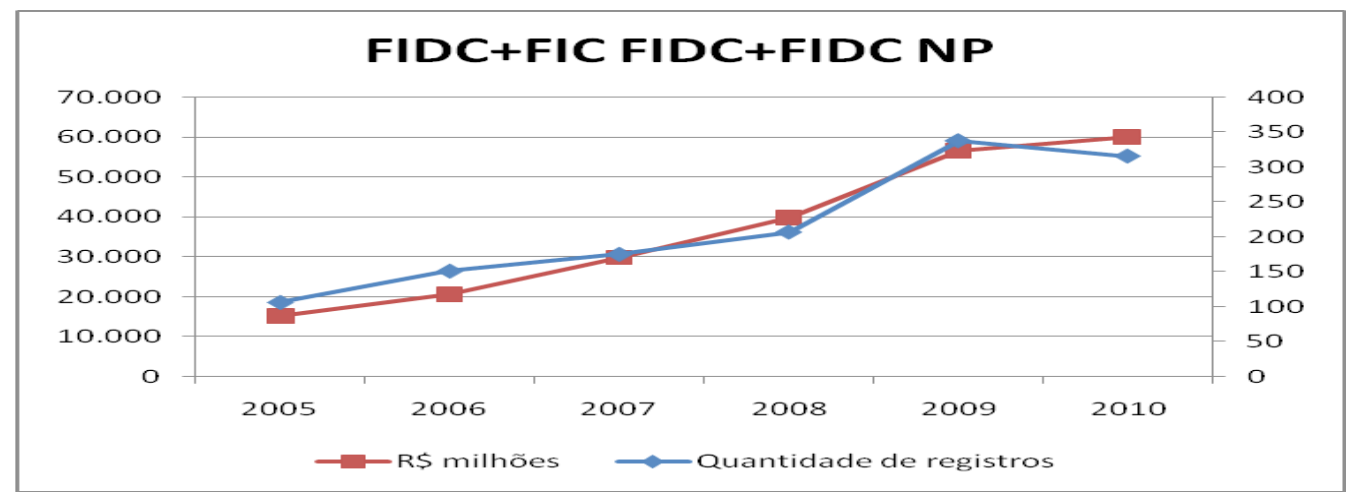

Figura 2. Evolução do PL em R\$ milhões e em quantidade de FIDCs registrados na CVM.

Fonte: CVM 2011.

Em relação ao PL, note um aumento cerca de $300 \%$ de 2005 para 2010 , e de $200 \%$ na quantidade dos FIDCs registrados na CVM. Pode-se observar que a evolução do PL vem aumentando em torno de R $\$ 10$ bi ao ano, de 2005 a 200, e, logo após a crise mundial financeira do subprime de 2008, o PL aumentou cerca de R\$ 20 bi até 2009. Esse pico está em consonância com os estudos internacionais de Dechow et al., (2010), no quae afirmam que as securitizações de ativos são atividades econômicas poderosas de captação de recursos, principalmente durante uma crise financeira, como ocorreu com o subprime em 2008.

\subsection{Regulamentação de Securitização de Ativos no Brasil}

O BACEN emitiu a Circular 2.568/95, na qual regulamentou que as operações de transferências e cessões de créditos com ou sem coobrigação são consideradas como vendas definitivas, procedendo à baixa dos ativos $\mathrm{e}$ apurando o ganho ou perda da operação no ato da venda. A contraparte registra os créditos em seu ativo. Esse é o tratamento contábil dispensado pelas empresas em nossa amostra, considerando-se que o período em análise neste estudo termina em dezembro de 2010. Isso permite que determinadas instituições realizem a transferência de seus ativos financeiros e antecipem o reconhecimento de ganhos, mesmo se a transação for realizada com um veículo ligado economicamente à instituição transferente/ cedente. Esse tratamento é diferente do tratamento preconizado atualmente pelas normas internacionais $\mathrm{e}$ pelas normas da CVM.

Importante salientar que recentemente, em consonância às normas internacionais de contabilidade, o CMN editou a Resolução 3.533/08, em 31 de janeiro de 2008, cujos efeitos estavam previstos para serem produzidos a partir de $1^{\circ}$ de janeiro de 2009 . O CMN postergou esses efeitos por três vezes, sendo para $1^{\circ}$ janeiro de 2010, 2011 e 2012 por meio das Resoluções 3.673 de 26/12/2008, 3.809 de 28/10/2009 e 3.895 de 29/07/2010, respectivamente (BACEN, 2008a, 2008b, 2009, 2010).

A complexidade do tema aparece em casos de dificuldade de tratamento contábil das referidas operações. Em 2010, por exemplo, a CVM determinou a republicação do balanço consolidado do Banco Cruzeiro do Sul S.A., relativo ao exercício findo em 31 de dezembro de 2008. A nota explicativa $\mathrm{n}^{\circ} 1$ esclarece o motivo pelo o qual foi necessário refazer e republicardas demonstrações financeiras dessa instituição de capital aberto, conforme a seguir:

Por determinação da CVM através do Ofício/CVM/SEP/ GEA-N $022 / 2010$, de 26 de janeiro de 2010, estamos reapresentando as demonstrações financeiras consolidadas de 31 de dezembro de 2008, para adotar o entendimento da CVM de que o cessionário final de uma operação de cessão efetuada em 30 de dezembro de 2008 (Prosper Flex FIDC Multicedentes - Nota Explicativa ${ }^{\circ} 3$ ), deve ser considerada como entidade pertencente à mesma unidade econômicaCconsolidada, devido a relevância do percentual de cotas seniores detidas pelo Banco em relação $\grave{a}$ totalidade de cotas do Fundo. A premissa adotada pela administração até o recebimento do referido oficio era de que a detenção de cotas seniores de um fundo, pelas suas características, não configurava o controle do mesmo e, por esta razão, o mesmo não era consolidado (BCSULSA, 2011). Esse procedimento de consolidação gerou um impacto negativo no resultado e no PL dessa instituição em R\$ 14.131 mil, alterando o resultado de um prejuízo de R\$ 116.442 mil para R\$ 130.573 mil (BCSULSA, 2011).

Adicionalmente, o Parecer do Comitê de Termo de Compromisso emitido pela CVM, divulgado ao mercado em 20 de outubro de 2010, informou a possibilidade de o BCSULS, ter utilizado mecanismos para melhorar o balanço por meio de cessão de direitos creditórios 
originados pelo próprio BCSULS, aos Fundos FIDC Aberto BCSUL Verax CPP 120 (FIDC CPP 120) e FIDC BCSUL Verax Multicred Financeiro (FIDC Multicred). Esses fundos, por sua vez, são administrados por empresas do conglomerado financeiro do BCSULSA (CVM, 2010).

\section{METODOLOGIA}

\subsection{Base de Dados}

Inicialmente, foram selecionadas as instituições financeiras (IF) que realizaram operações com securitização de ativos no período de janeiro de 2002 a dezembro de 2010. O período em análise se justifica a partir da Instrução n ${ }^{\circ} 356$ de 17 de Dezembro de 2001, quando a CVM regulamentou a constituição e o funcionamento dos FIDCs.

Em relação à coleta dos dados, relacionaram-se todos os FIDCs registrados nas categorias "Cotas registradas" e "Dispensada de registro", junto à CVM. Identificaramse 552 observações relativas à criação ou ao lançamento de nova série de FIDC. Com o objetivo de identificar as instituições cedentes, foram analisados os prospectos e/ ou as DFs, divulgados no site da CVM, para cada um destes FIDCs.

Após a análise dos prospectos e/ou das DFs, encontraram-se 133 observações originadas por IFs, 297 por demais tipos de instituições e para as 122 restantes, por falta de informação, não foi possível identificar as instituições cedentes e/ou originadoras.rEsta pode ser considerada uma limitaçãondesta pesquisa, no caso de o cedente/originador não ter sido identificado coma uma instituição financeira e, sendo assim, tal instituição não compôs a amostra. Nas 133 observações dos FIDCs onde as cedentes são as IFs, identificaram-se 34 instituiçõe, e, em função da disponibilidade dos dados, a base da amostra foi composta por 28 IFs. Por fim, foram analisadas as DFs, para o período estudado, das $28 \mathrm{IFs}$ cedentes a FIDCs.

Para formar uma base maior de observações, incluíram-se todos os períodossdessas IFs que realizaram operações com securitização. Ou seja, independentemente de a securitização ter sido com FID, ou com outro tipo de cessionário (por exemplo, outra IF), a IF entrou na base de dados.

Cumpre destacar a possibilidade de viés na amostra, uma vez que a amostra foi composta apenas por IFs que realizaram securitização.

\subsection{Modelo Empírico}

Esta pesquisa é de natureza quantitativa eáirá se basear ne análise descritiva e no cruzamento de informações, além de regressão para avaliação das relações de interesse, em conformidade com o modelo de
Dechow et al., (2010).

O objetivo da metodologia utilizada é testar as seguintes hipóteses de pesquisa:

Hipótese 1: Resultados com securitização se relacionam negativamente com o resultado antes da securitização das IFs.

Hipótese 2: Resultados com securitização se relacionam negativamente com variações no resultado antes da securitização das IFs.

Hipótese 3: A constituição de um FIDC por IF eleva o resultado com securitização.

As hipóteses (1) e (2) foram inspiradas em duas circunstâncias dos estudos de Dechow et al., (2010). A primeira se dá quando os resultados antes da securitização (resultados antes do ganho de securitização) são baixos. Nesse caso, os gestores enfrentam um maior escrutínio pelos investidores e reguladores, e tendem receber menos bônus e opções, e terão mais problemas para atrair empregados e clientes. Assim, haverá incentivos de registrar resultados atuais mais altos e então a instituição registrará um ganho discricionário. Do mesmo modo, quando os resultados antes da securitização são altos, os gestores têm menos incentivos para registrar ganhos e poderiam até preferir registrar uma perda.oDesse modo, a instituição registrará uma perda discricionária. A segunda circunstância é quando o resultado antes da securitização está abaixo do nível do ano anterior; nesse caso o resultado com securitização tende a ser maior.

A terceira hipótese trate de uma contribuição adicional ao estudo de securitização, por se tratar de um tipo de securitização em que se espera que as operações com FIDCs influenciem o resultado com securitização.

O aprofundamento da análise será realizado por meio de uma regressão de dados em painel o qual permite identificar a relação proposta na introdução, sendo esta uma adaptação do modelo desenvolvido por Dechow et al., (2010).

Res_sec ${ }_{\mathrm{it}}=\beta_{0}+\beta_{1} \mathrm{Vpse}_{\mathrm{it}}+\beta_{\mathrm{n}} \mathrm{X}_{\mathrm{nit}}+\beta_{3} \mathrm{Dfidc}_{\mathrm{it}}+\boldsymbol{\varepsilon}_{\mathrm{it}}(1)$

$\operatorname{Res} \_s e c_{\mathrm{it}}=\beta_{0}+\beta_{1} \Delta \mathrm{Vpse}_{\mathrm{it}}+\beta_{\mathrm{n}} \mathrm{Xn}_{\mathrm{it}}+\beta 3 \mathrm{Dfidc}_{\mathrm{it}}+\boldsymbol{\varepsilon}_{\mathrm{it}}(2)$

onde:

Res_sec : Variável Resultado com Securitização da IF $i$ no ano $t$.

VPSE $_{\mathrm{it}}$ : Variável Resultado antes da Securitização da IF $i$ no ano $t$.

$\mathrm{Xn}_{\mathrm{it}}:$ Vetor das variáveis de controle da IF $i$ no ano $t$.

$\Delta$ Vpse $_{\text {it }}$ : Variável da Variação do Resultado antes da Securitização da IF $i$ no ano $t$.

Dfidc $_{\mathrm{it}}:$ : Variável dummy que assumirá 1 quando a IF apresentar um FIDC constituído, caso contrário, zero.

$\boldsymbol{\varepsilon}_{\mathrm{it}}:$ Termo de erro aleatório 
A análise da regressão acima recai sobre o coeficiente $\beta_{1}$. Caso seu sinal seja negativo, haverá evidências que permitem inferir a existência da relação negativa entre o resultado antes da securitização e o resultado de securitização, corroborando a hipótese de gerenciamento de resultados.

Adicionalmente, torna-se interessante a captação da informação referente ao impacto da criação do FIDC no resultado com securitização. Dessa forma, incluiu-se uma variável dummy (qualitativa) que identifica a existência de FIDC na IF.

Caso o coeficiente estimado para as variáveis dummy dos modelos acima seja positivo eesignificativo, encontram-se evidências de que a criação de um FIDC cause impacto no resultado com securitização, possivelmente proveniente de gerenciamento de resultados.

\subsection{Operacionalização das Variáveis}

As informações foram coletadas por meio dos saldos contábeis registrados nas DFs, bem como nas notas explicativas das IFs. Estas, por sua vez, são divulgadas nos respectivos sites institucionais, do BACEN por meio das Informações Financeiras Trimestrais (IFT) e da CVM por meio das Demonstrações Financeiras Padronizadas (DFP).

As variáveis descritas por Dechow et al., (2010), aqui, foram operacionalizadas de forma a se adequarem aos dados brasileiros e são padronizadas em termos do
PL com o escopo de evitar distorções dos valores entre as IFs, eliminando assi, o problema relativo ao "tamanho" dassinstituições. O PL foi utilizado por constituir uma medida de capital mais significativa que os ativos, em função de estes estarem mais sujeitos ao gerenciamento wDECHOW et al., 2010).

As variáveis de controle foram inseridas com o objetivo de retirar uma possível correlação entre o termo de erro e as variáveis explicativas, fato este que poderia causar viés nas estimativas encontradas.

\section{RESULTADOS}

\subsection{Estatística Descritiva}

A aplicação da metodologia, nesta seção de resultados, inicia-se apresentando as estatísticas descritivas das variáveis de interesse na análise. Dentre elas, pode-se destacar a média, desvio padrão, mínimos e máximos das variáveis.

Os dados contidos na Tabela 1 referem-se a 28 IFs, considerando o período em análise, das quais foram coletadas 144 observações para todas as variáveis, exceto para a variável controle "Fluxo de Caixa antes da Securitização", na qual foram disponibilizadas 75 observações. Isso porque as IFs passaram a publicar as Demonstrações de Fluxo de Caixa, a partir de 2008, com saldo comparativo a 2007.

Tabela 1. Estatística Descritiva

\begin{tabular}{l|c|c|c|c|c}
\hline \multicolumn{1}{c|}{ Descrição } & N & Média & Desvio Padrão & Mínimo & Máximo \\
\hline Resultado com Securitização & 144 & 0,4761 & 0,7408 & $-0,6133$ & 3,3877 \\
\hline Resultado antes da Securitização & 144 & $-0,1882$ & 0,6697 & $-2,8514$ & 2,0559 \\
\hline Variação do Resultado antes da Securitização & 144 & $-0,1023$ & 0,6091 & $-3,1714$ & 3,2342 \\
\hline Resultado com Securitização do Setor & 144 & 0,1808 & 0,3920 & 0,0005 & 2,9913 \\
\hline Média do Retorno sobre o PL médio & 144 & 0,2213 & 0,1224 & $-0,1083$ & 0,5341 \\
\hline Taxa de Desconto & 144 & 0,1215 & 0,1528 & $-0,7860$ & 0,4890 \\
\hline Fluxo de Caixa antes da Securitização & 75 & $-4,6914$ & 6,4599 & $-32,2736$ & 1,7278 \\
\hline Segmento & 144 & 0,7778 & 0,4172 & 0 & 1 \\
\hline Regulamentação & 144 & 0,2222 & 0,4172 & 0 & 1 \\
\hline Fidc & 144 & 0,4097 & 0,4935 & 0 & 1 \\
\hline Resultado Líquido do Exercício & 144 & 102.376 & 164.058 & -142.244 & 1.207 .639 \\
\hline Ativo Total & 144 & 4.761 .585 & 10.289 .051 & 37.905 & 66.870 .823 \\
\hline PL & 144 & 961.335 & 3.332 .486 & 10.718 & 24.438 .905 \\
\hline
\end{tabular}

Nota (1): Resultado com Securitização Resultado: obtido com a securitização dividido pelo PL do exercício anterior; Resultado antes da Securitização: Resultado líquido do exercício deduzido do "RESULTADO COM SECURITIZAÇÃO", dividido pelo PL do exercício anterior; Variação do resultado antes da Securitização: O "RESULTADO ANTES DA SECURITIZAÇÃO" do exercício atual, reduzido do "RESULTADO ANTES DA SECURITIZAÇÃO" do exercício anterior, dividido pelo PL do exercício anterior; Resultado com Securitização do Setor: Calculado a partir da mediana do "RESULTADO COM SECURITIZAÇÃO" do ano, dividido pelo PL do exercício anterior; Média do Retorno sobre o PL Médio: Média dos últimos cinco anos do retorno do PL (ROE) de cada instituição; Taxa de desconto: Quociente apurado entre o valor presente da venda do título securitizado (cessão) e o valor presente desse título registrado na contabilidade; Fluxo de caixa antes da Securitização: Somatório do fluxo de caixa operacional com o fluxo de caixa de investimento, deduzido pelo valor recebido na venda do título securitizado (cessão), dividido pelo PL do ano anterior; Regulamentação: Variável dummy que assumirá 1, quando a IF 
for regulamentada pela CVM; Fidc: Variável dummy que assumirá 1, quando a IF apresentar um FIDC constituído ou lançamento de uma nova série.

Nota (2): Os valores apresentados nas colunas de mínimo e máximo para as observações "Resultado Líquido do Exercício, Ativo Total e PL" estão expressos em milhares de reais, já para "Segmento, Regulamentação e Criação de Fidc" por se tratarem de variáveis dummy, assumirão 1 (um) quando existir ou 0 (zero) caso contrário. As demais variáveis estão representadas em forma de índice, em função das mesmas serem escalonadas pelo PL das IFs.

Torna-se interessante analisar que a taxa média de desconto das operações com securitização foi de 0,1215 , enquanto o resultado com securitização do setor foi de 0,1808 . Outro fato interessante foi a média Fluxo de Caixa antes da Securitização ser $-4,67$, indo em conformidade com a média de $-4,57$ encontrada por Dechow et al., (2010). Observou-se ainda que houve a criação de FIDC em $41 \%$ das observações, e $22 \%$ delas se apresentam-se com regulamentação da CVM.

Dechow et al., (2010) afirmam que quando uma empresa "vende" seus recebíveis ela recebe caixa, e qualquer diferença é registrada como um ganho ou perda referindo a este efeito da renda como um "ganho", uma vez que os ganhos são típicos no processo de securitização de ativos. De acordo com a predição da literatura internacional, os resultados naquele estudo relataram que $76 \%$ das observações são ganhos, $15 \%$ perdas e $9 \%$ têm efeito zero sobre o ganho. Os resultados deste estudo revelam que $85 \%$ das observações reportaram ganho, $9 \%$ prejuízo e $6 \%$ não apresentaram ganho nem prejuízo com securitização.

\subsection{Resultados Empíricos}

As regressões apresentadas, anteriormente, nas equações (1) e (2), foram estimadas por dados em painel com efeitos fixos, por considerar que os fatores não observáveis, invariantes no tempo são não aleatórios. Cabe observar que os dados constituem um painel não balanceado, pois há instituições para as quais os dados não foram identificáveis, nas respectivas notas explicativas para todo o período.

A Quadro 1 descreve a predição dos sinais para cada variável de interesse utilizada neste estudo.

\begin{tabular}{|c|c|c|}
\hline VARIÁVEL & SINAL & PREDIÇÃO \\
\hline $\begin{array}{l}\text { Resultado antes da Securitização } \\
\text { e Variação do Resultado antes da } \\
\text { Securitização }\end{array}$ & - & $\begin{array}{l}\text { De acordo com os estudos de Dechow, Myers e Shakespeare, } 2009 \text {, os gestores tendem } \\
\text { registrar ganhos de securitização quando os resultados pré estão baixos ou abaixo do } \\
\text { ano anterior. Portanto, espera-se uma correlação negativa com o resultado antes da } \\
\text { securitização. }\end{array}$ \\
\hline \multicolumn{3}{|l|}{ Controles } \\
\hline $\begin{array}{l}\text { Resultado com Securitização do } \\
\text { Setor }\end{array}$ & + & $\begin{array}{l}\text { Dechow, Myers e Shakespeare, } 2009 \text {, preveem que o resultado com securitização seja } \\
\text { ganho e, por se tratar da mediana dos resultados com securitização do setor, espera-se } \\
\text { uma correlação positiva. }\end{array}$ \\
\hline $\begin{array}{l}\text { Média do Retorno sobre o PL } \\
\text { médio }\end{array}$ & + & $\begin{array}{l}\text { Dechow, Myers e Shakespeare, } 2009 \text {, preveem que o resultado com securitização seja } \\
\text { ganho, logo se espera uma correlação positiva, uma vez que esse ganho afeta o lucro e, } \\
\text { por conseguinte, o valor do PL. }\end{array}$ \\
\hline Taxa de desconto & + & $\begin{array}{l}\text { Como neste estudo não se encontrou a taxa de desconto divulgada em notas explicativas, } \\
\text { então esta foi calculada por meio do valor de venda do título, escalonado pelo valor } \\
\text { registrado no ativo e, dessa forma, espera-se um sinal positivo, uma vez que quanto maior } \\
\text { esta taxa de desconto, maior será o ganho com securitização. }\end{array}$ \\
\hline $\begin{array}{l}\text { Fluxo de Caixa antes da } \\
\text { Securitização }\end{array}$ & - & $\begin{array}{l}\text { Conforme Dechow, Myers e Shakespeare, } 2009 \text {, empresas com mais fluxos de caixa livres } \\
\text { negativos são mais tendentes a precisar de financiamento adicional e de se engajar em uma } \\
\text { extensão maior de securitizações. Portanto, espera-se uma relação negativa. }\end{array}$ \\
\hline Criação Fidc & + & $\begin{array}{l}\text { FIDC é uma modalidade de securitização, espera-se que quanto maior o volume de } \\
\text { operações com FIDC, maior será o ganho com securitização. }\end{array}$ \\
\hline
\end{tabular}

Quadro 1. Sinais esperados entre as variáveis na regressão

Nota: Resultado antes da Securitização: Resultado líquido do exercício deduzido do "RESULTADO COM SECURITIZAÇÃO", dividido pelo PL do exercício anterior; Variação do resultado antes da Securitização: O "RESULTADO ANTES DA SECURITIZAÇÃO" do exercício atual, reduzido do "RESULTADO ANTES DA SECURITIZAÇÃO” do exercício anterior, dividido pelo PL do exercício anterior; Resultado com Securitização do Setor: Calculado a partir da mediana do "RESULTADO COM SECURITIZAÇÃO" do ano, dividido pelo PL do exercício anterior; Média do Retorno sobre o PL Médio: Média dos últimos cinco anos do retorno do PL (ROE) de cada instituição; Taxa de desconto: Quociente apurado entre o valor presente da venda do título securitizado (cessão) e o valor presente deste título registrado na contabilidade; Fluxo de caixa antes da Securitização: Somatório do fluxo de caixa operacional com o fluxo de caixa de investimento, deduzido pelo valor recebido na venda do título securitizado (cessão), dividido pelo PL do ano anterior; Criação Fidc: Variável dummy que assumirá 1, quando a IF apresentar um FIDC constituído ou lançamento de uma nova série. 
Na Tabela 2, são reportados os resultados obtidos considerando a equação (1).

Tabela 2. Regressão entre o Resultado com Securitização e seus Determinantes

\begin{tabular}{|c|c|c|c|c|}
\hline \multicolumn{5}{|c|}{ Variável dependente: Resultado com securitização } \\
\hline & Sinal predito & (1) & (2) & (3) \\
\hline \multirow[t]{2}{*}{ Intercepto } & & $0,3108^{(*)}$ & $-0,1634$ & $-0,1344^{(*)}$ \\
\hline & & $(10,66)$ & $(-1,57)$ & $(-1,73)$ \\
\hline \multirow[t]{2}{*}{ Resultado antes da Securitização } & - & $-0,8781^{(*)}$ & $-0,7325^{(*)}$ & $-0,9573^{(*)}$ \\
\hline & & $(-14,84)$ & $(-12,91)$ & $(-18,86)$ \\
\hline \multicolumn{5}{|l|}{ Controles } \\
\hline \multirow[t]{2}{*}{ Resultado com Securitização do Setor } & + & & $0,6048^{(*)}$ & 0,1052 \\
\hline & & & $(3,44)$ & $(-0,78)$ \\
\hline \multirow[t]{2}{*}{ Média do Retorno sobre o PL médio } & + & & $1,3293^{(*)}$ & $1,2267^{(*)}$ \\
\hline & & & $(2,85)$ & $(3,18)$ \\
\hline \multirow[t]{2}{*}{ Taxa de desconto } & + & & $0,4182^{(*)}$ & 0,0528 \\
\hline & & & $(2,08)$ & $(0,45)$ \\
\hline \multirow[t]{2}{*}{ Fluxo de caixa antes da Securitização } & - & & & $-0,0248^{(*)}$ \\
\hline & & & & $(-4,79)$ \\
\hline \multirow[t]{2}{*}{ Criação Fidc } & + & & $0,1154^{(*)}$ & $-0,0622$ \\
\hline & & & $(2,02)$ & $(-1,49)$ \\
\hline Número de observações & & 144 & 144 & 75 \\
\hline R2 ajustado & & 0,6568 & 0,7503 & 0,9488 \\
\hline
\end{tabular}

Nota: Resultado antes da Securitização: Resultado líquido do exercício deduzido do "RESULTADO COM SECURITIZAÇÃO", dividido pelo PL do exercício anterior; Resultado com Securitização do Setor: Calculado a partir da mediana do "RESULTADO COM SECURITIZAÇÃO" do ano, dividido pelo PL do exercício anterior; Média do Retorno sobre o PL médio: Média dos últimos cinco anos do retorno do PL (ROE) de cada instituição; Taxa de desconto: Quociente apurado entre o valor presente da venda do título securitizado (cessão) e o valor presente deste título registrado na contabilidade; Fluxo de caixa antes da Securitização: Somatório do fluxo de caixa operacional com o fluxo de caixa de investimento, deduzido pelo valor recebido na venda do título securitizado (cessão), dividido pelo PL do ano anterior; Criação Fidc: Variável dummy que assumirá 1, quando a IF apresentar um FIDC constituído ou lançamento de uma nova série.Os valores entre parênteses reportam a estatística t para cada coeficiente. ${ }^{(*)}$ Valores significativos a $10 \%$

Nota-se que a relação entre resultado com securitização e resultado antes da securitização é negativa e significativa em todos os modelos, conforme esperado em uma situação de gerenciamento de resultados. O modelo (1) descreve uma regressão simples e apresenta um efeito marginal, indicando que, para uma variação unitária no resultado antes da securitização, há queda no resultado com a securitização de aproximadamente 0,88. Esse achado vai ao encontro do trabalho de Dechow et al., (2010), que verificaram uma queda no resultado com a securitização de aproximadamente 0,61 .

O modelo (2) inclui variáveis de controle de modo a reduzir a possível correlação entre a variável explicativa e o termo de erro, eliminando um possível viés da variável omitida.

O resultado indica uma pequena alteração no coeficiente de interesse, mas ainda o mantém negativo em 0,73. Pode-se observar também que a inclusão de uma dummy que capta a criação de FIDC apresenta um resultado significativo, indicando que a criação de FIDC causa impacto no resultado com securitização.

A inclusão do Fluxo de Caixa antes da Securitização, como variável controle, ocorre no modelo (3), o que diminui o tamanho da amostra.
Os resultados anteriormente encontrados parecem ser robustos à inclusão dessa nova variável, já que o resultado antes da securitização continua significativo, apresentando um aumento, em termos absolutos, do coeficiente para -0,96. Esse modelo indica que a criação de FIDC não interfere no resultado com securitização, já que a variável se mostrou não significativa.

Além disso, foi estimada uma regressão na qual a variável explicativa é a variação no resultado antes da securitização. Novamente, os resultados indicam relação negativa e significativa entre as variáveis. A Tabela 3 reporta os resultados obtidos considerando a equação (2): 
Tabela 3. Regressão entre o Resultado com Securitização e seus Determinantes

\begin{tabular}{|c|c|c|c|c|}
\hline \multicolumn{5}{|c|}{ Variável dependente: Resultado com securitização } \\
\hline & Sinal predito & (1) & (2) & (3) \\
\hline \multirow[t]{2}{*}{ Intercepto } & & $0,4247^{(*)}$ & $-0,3433^{(*)}$ & 0,0012 \\
\hline & & $(10,96)$ & $(-2,50)$ & $(0,01)$ \\
\hline \multirow[t]{2}{*}{ Variação do Resultado antes da Securitização } & - & $-0,5020^{(*)}$ & $-0,3980^{(*)}$ & $-0,5749^{(*)}$ \\
\hline & & $(-7,25)$ & $(-6,69)$ & $(-10,76)$ \\
\hline \multicolumn{5}{|l|}{ Controles } \\
\hline \multirow[t]{2}{*}{ Resultado do Setor } & + & & $0,9742^{(*)}$ & $-0,1363$ \\
\hline & & & $(4,26)$ & $(-0,62)$ \\
\hline \multirow[t]{2}{*}{ Média do Retorno sobre o PL médio } & + & & $2,1503^{(*)}$ & 0,4110 \\
\hline & & & $(3,46)$ & $(0,68)$ \\
\hline \multirow[t]{2}{*}{ Taxa de desconto } & + & & $0,5917^{(*)}$ & 0,1681 \\
\hline & & & $(2,21)$ & $(0,91)$ \\
\hline \multirow[t]{2}{*}{ Fluxo de caixa antes da Securitização } & - & & & $-0,0599$ \\
\hline & & & & $(-7,45)$ \\
\hline \multirow[t]{2}{*}{ Criação Fidc } & + & & $0,1338^{(*)}$ & $-0,0461$ \\
\hline & & & $(1,75)$ & $(-0,70)$ \\
\hline Número de observações & & 144 & 144 & 75 \\
\hline R2 ajustado & & 0,3140 & 0,5550 & 0,8734 \\
\hline
\end{tabular}

Nota: Variação do resultado antes da Securitização: "RESULTADO ANTES DA SECURITIZAÇÃO” do exercício atual, reduzido do "RESULTADO ANTES DA SECURITIZAÇÃO” do exercício anterior, dividido pelo PL do exercício anterior; Resultado com Securitização do Setor: Calculado a partir da mediana do "RESULTADO COM SECURITIZAÇÃO" do ano, dividido pelo PL do exercício anterior; Média do Retorno sobre o PL médio: Média dos últimos cinco anos do retorno do PL (ROE) de cada instituição; Taxa de desconto: Quociente apurado entre o valor presente da venda do título securitizado (cessão) e o valor presente deste título registrado na contabilidade; Fluxo de caixa antes da Securitização: Somatório do fluxo de caixa operacional com o fluxo de caixa de investimento, deduzido pelo valor recebido na venda do título securitizado (cessão), dividido pelo PL do ano anterior; Criação Fidc: Variável dummy que assumirá 1, quando a IF apresentar um FIDC constituído ou lançamento de uma nova série. Os valores entre parênteses reportam a estatística t para cada coeficiente. ${ }^{(*)}$ Valores significativos a $10 \%$

Verifica-se, igualmente, que a relação entre a variação do resultado antes da securitização e do resultado com securitização permanece inversa e significativa. No modelo de regressão simples, observou-se um coeficiente de $-0,50$. Esse achado vai ao encontro do trabalho de Dechow et al., (2010), no qual encontraram uma queda no resultado com a securitização de aproximadamente 0,57.

A magnitude cai com a inclusão de variáveis de controle, todavia, o sinal e a significância da relação permanecem. Não há forte evidência de que a criação de FIDC exerce influência sobre o resultado com securitização, pois apenas no modelo 2 a variável apresenta coeficiente significativo.

\section{CONSIDERAÇÕES FINAIS}

O presente trabalho encontrou resultados alinhados com a literatura internacional, conforme o trabalho realizado por Dechow et al., (2010) sobre o gerenciamento de resultados, partindo do pressuposto de que o ganho com securitização é uma forma de gerenciar resultados em função da flexibilidade das regras contábeis, referentes ao registro pelo valor justo.

Nesse sentido, chegou-se a outra premissa: quando os resultados antes da securitização são inferiores aos do ano anterior, pressupõe-se a existência de maiores ganhos com securitização.

Outra hipótese, a de que a criação de FIDC por uma instituição eleva os resultados com securitização, não encontrou sustentação nesta pesquisa. Entretanto, uma possível justificativa para esse resultado é que o fato de o resultado antes da securitização ser inferior ao do exercício anterior é mais importante que a criação de um FIDC.

Em consonância com o trabalho de Dechow et al., (2010), a falta de divulgações detalhadas sobre a taxa de desconto utilizada em transações específicas de securitização limitou a análise empírica. Outro fator que limitou a coleta de dados nesta pesquisa foi a falta de divulgação de resultado com cessão de crédito, notadamente a FIDC. Nesse aspecto, recomendase o aprimoramento das divulgações, a respeito das securitizações de ativos nas notas explicativas das IFs.

Corroborando a literatura internacional, este trabalho encontrou evidências de que os gestores utilizam a discricionariedade presente nas transações de 
securitização para suavizar o resultado das IFs. Portanto, não é possível discernir se o gerenciamento de resultados observado é relativo à discrição na estimativa do montante do ganho de securitização, à discrição nas quais os ativos serão securitizados ou à discrição em decisões negociais, como por exemplo, a taxa de desconto.

O CMN editou a Resolução 3.533/08, em 31 de janeiro de 2008, na qual define que um ativo deve ser baixado somente quando houver transferência substancial de riscos e benefícios (ou permanecer reconhecido quando houver retenção substancial de riscos e benefícios). No caso da retenção substancial, a IF passará a apropriar o ganho ou a perda com a securitização no prazo remanescente da operação. Essa Resolução entrará em vigor a partir de 2012. Sendo assim, as DFs individuais das IFs estarão em consonância com as normas internacionais de contabilidade.

Como sugestão para pesquisas futuras recomendase a replicação deste estudo, tendo por base as DFs das IFs após a entrada em vigor da Resolução 3.533/08, em busca de achados que confirmem ou refutem a hipótese de gerenciamento de resultados que tenham por base ativos securitizados. Outra pesquisa sugerida é a busca de uma correlação entre os ganhos de securitização e bônus dos CEOs.

Apesar de o assunto gerenciamento de resultados ser bem difundido na literatura internacional, quando se trata do correlacionamento com a securitização de ativos em IFs, a questão ainda não é muito explorada, inclusive no Brasil. Um dos motivos pode ser a grande dificuldade em coletar dados, principalmente em função da falta de divulgação de informações nas DFs por parte das IFs.

\section{REFERÊNCIAS}

\section{ASSOCIAÇÃO NACIONAL DAS INSTITUICÕ̃ES} DO MERCADO FINANCEIRO; Fundo de Investimento de Direitos Creditórios. Câmara de Custódia e Liquidação. Rio de Janeiro: Stamppa. 2006

BANCO CENTRAL DO BRASIL. Circular 2.568 de 04 de maio de 1995. Altera a classificação de fatores de risco de operações ativas, bem como os procedimentos para contabilização de operações de cessão de crédito e de receitas e despesas a apropriar. Diário Oficial [da] Republica Federativa do Brasil, Brasília, 05 mai. 1995. Disponível em: $<$ http://www.bcb.gov.br/pre/ normativos/circ/1995/ pdf/circ_2568.pdf>.

BANCO CENTRAL DO BRASIL. Resolução 3.533, de 31 de janeiro de 2008. Estabelece procedimentos para classificação, registro contábil e divulgação de operações de venda ou de transferência de ativos financeiros. Diário Oficial [da] Republica Federativa do Brasil, Brasilia, 01 fev. 2008 Disponível em: <http://www.bcb.gov.br/pre/ normativos $/$ busca/normativo.asp?tipo $=$ Res $\&$ ano $=2$ $008 \&$ numero $=3533>$.

BANCO CENTRAL DO BRASIL. Resolução 3.673 de 26 de dezembro de 2008. Dispõe sobre a adoção dos procedimentos de classificação, registro contábil e divulgação das operações de venda ou de transferência de ativos financeiros de que trata a Resolução 3.533, de 2008. Diário Oficial [da] Republica Federativa do Brasil, Brasília, 27 dez. 2008. Disponível em: <http://www.bcb.gov.br/pre/ normativos/res/2008/pdf/res_3673.pdf>

BANCO CENTRAL DO BRASIL. Resolução 3.809 de 28 de outubro de 2009. Dispõe sobre a adoção de procedimentos de classificação, registro contábil e divulgação das operações de venda ou transferência de ativos financeiros de que se trata a Resolução 3.533, de 2008. Diário Oficial [da] Republica Federativa do Brasil, Brasília, 29 out. 2009. Disponível em: <http://www.bcb.gov.br/pre/ normativos/res/2009/pdf/res_3809.pdf>

BANCO CENTRAL DO BRASIL. Resolução 3.895 de 29 de julho de 2010. Altera a Resolução 3.809 de 28 de outubro de 2009, que dispõe sobre a adoção dos procedimentos de classificação, registro contábil e divulgação das operações de venda ou transferência de ativos financeiros de que trata a resolução 3.533 de 31 de janeiro de 2008. Diário Oficial [da] Republica Federativa do Brasil, Brasília 30 jul. 2010. Disponível em: <http://www.bcb.gov.br/pre/ normativos/res/2010/pdf/res_3895.pdf $>$

BANCO CRUZEIRO DO SUL S.A. Demonstrações financeiras em 31 de dezembro de 2008 e 2007. Disponível em: <http://www.mzweb.com.br/ cruzeirodosul/ web/arquivos/BCSul_DFs_2008 completa_fev20100209_port.pdf>

BRASIL. Lei $n^{\circ} 11.638$, de 28 de dezembro de 2007. Dispõe sobre Alteração, Dispositivos, Lei das Sociedades Anônimas. Diário Oficial [da] Republica Federativa do Brasil, Brasília, 28 dez. 2007. Disponível em: <http://www.planalto.gov.br/ ccivil 03/ ato2007-2010/2007/lei/111638.htm>

CARVALHO, L. N.; PAULO, E.; RODRIGUES, A. Gerenciamento de resultados por meio das transações entre companhias brasileiras interligadas. RAUSP, v. 42, n. 2, p. 216-226, 2007.

CUPERTINO, C. M.; MARTINEZ, A. L. Qualidade da auditoria e earnings management: risk assessment através do nível dos Accruals Discricionários. Revista de Contabilidade Vista e Revista, v. 19, n. 3, p. 69-93, 2008.

COMISSÃO DE VALORES MOBILIÁRIOS. 2011. Disponível em: http://www.cvm.gov.br

COMISSÃO DE VALORES MOBILIÁRIOS. OfícioCircular CVM-SNC-SEP 01/2006, 2006. Disponível em: $<$ http://www.cvm.gov.br $>$ 
COMISSÃO DE VALORES MOBILIÁRIOS. Parecer do Comitê de Termo de Compromisso de 20 de outubro de 2010. REF.: Processo administrativo CVM No RJ2009/2917. Disponível em: <www. cvm.gov.br/port/descol/respdecis.asp?File=7289-0. HTM>

DECHOW, P. M.; MYERS, L.; SHAKESPEARE, C. Fair value accounting and gains from asset securitizations: A convenient earnings management tool with compensation side-benefits. Journal of Accounting and Economics, v. 49, n. 1-2, p. 2-25, 2010.

FIELDS, T. D., LYS, T. Z., \& VINCENT, L. Empirical research on accounting choice. Journal of Accounting and Economics, v. 31, n. 1-3, p. 255307, 2001.

GALDI, F. C. et al. Securitização. In: LIMA, I. S.; LIMA, G. A. S. F.; PIMENTEL, R. C. (Org.). Curso de mercado financeiro. p. 170-216. São Paulo: Atlas.

GOULART, A. M. C. Gerenciamento de resultados contábeis em instituições financeiras no Brasil. Tese (Doutorado em Ciências Contábeis) - Faculdade de Economia, Administração e Contabilidade da Universidade de São Paulo (USP), São Paulo, 2007.

IG. Banco Central justifica adiamento da resolução $n^{0}$ 3.533. 2010. Disponível em: <http://economia. ig.com.br/mercados/banco+central+justifica+adia mento $+\mathrm{da}+$ resolucao $+\mathrm{n}+3533 / \mathrm{n} 1237852538777$. html>. Acessado: 17 de novembro de 2011.

IUDÍCIBUS, S.; MARTINS, E.; GELBECKE, E. R.; SANTOS, A. Manual de contabilidade societária: aplicável a todas as sociedades de acordo com as normas internacionais e do CPC. São Paulo: Atlas, 2010 .

KOTHARI, S. P. Capital markets research in accounting. Journal of Accounting and Economics, v. 31, n.13 , p. 105-231, 2001..

MCNICHOLS, M. Research design issues in earnings management. Journal of Accounting and Public Policy, v. 19, n.4-5, p.313-345, 2000.

PAULO, E.; SANTOS, A. Diferimento das perdas cambiais como instrumento de gerenciamento de resultados. Brazilian Business Review. v. 3, n. 1, p. 15-31, 2006.

SCHWARCZ, S. The Future of Securitization. Connecticut Law Review. v. 41, n. 4, p. 13131324, 2009.

\section{AGRADECIMENTOS:}

Á FAPES (Fundação de Amparo à Pesquisa do Espírito Santo) pelo apoio recebido. 